\title{
Image-guided Interstitial Brachytherapy in the Management of Metastasized Anal Squamous Cell Carcinoma
}

\author{
CONSTANZE HEINZE ${ }^{1}$, JAZAN OMARI ${ }^{1}$, MAX OTHMER ${ }^{1}$, PETER HASS ${ }^{2}$, MAX SEIDENSTICKER ${ }^{3}$, \\ ROBERT DAMM ${ }^{1}$, JENS RICKE ${ }^{3}$, MACIEJ PECH ${ }^{1,4}$ and MACIEJ J. POWERSKI ${ }^{1}$ \\ ${ }^{1}$ Department of Radiology and Nuclear Medicine, ${ }^{2}$ Radiation Oncology, \\ Otto-von-Guericke University, Magdeburg, Germany; \\ ${ }^{3}$ Department of Radiology, University Hospital Munich, Munich, Germany; \\ ${ }^{4}$ Second Department of Radiology, Medical University of Gdansk, Gdansk, Poland
}

\begin{abstract}
Background/Aim: Interstitial brachytherapy (IBT) has been shown to provide high tumor control rates in metastatic colorectal carcinoma. Our aim was to evaluate efficacy and safety of IBT in patients with metastatic anal squamous cell carcinoma (mASCC). Patients and Methods: Seven patients with a total of 38 unresectable ASCC metastases (28 liver, nine lung, one nodal metastases) were treated with computed tomographic or open magnetic resonance imaging-guided IBT using an iridium-192 source. Clinical and image-based follow-up were performed every 3 months after treatment. Results: Local tumor control rate was $97.4 \%$ during a median follow-up of 15.2 months. Median progression-free survival was 3.3 months (range $=2.5-32.6$ months). Median overall survival after IBT was 25.2 months (range=6.5-51.0 months). No severe adverse events (grade 3 or more) were recorded. Conclusion: Image-guided IBT is a safe and particularly effective treatment in patients with mASCC and might provide a welltolerated therapeutic option in a multidisciplinary setting.
\end{abstract}

Squamous cell cancer is the dominant histological type in cancer of the anal canal; it is a rather rare malignancy with approximately 27,000 new cases worldwide in 2008 , although the incidence is constantly rising $(1,2)$. In around $70-90 \%$ of cases it is associated with human papilloma virus infection, and immunosuppression is another risk factor of great significance, accounting for an elevated incidence rate in HIV-infected individuals $(3,4)$. Five-year overall survival

Correspondence to: Constanze Heinze, Department of Radiology and Nuclear Medicine, Otto-von-Guericke University, Leipziger Strasse 44, 39120 Magdeburg, Germany. Tel: +49 3916713030, Fax. +49 3916713029, e-mail: constanze.heinze@med.ovgu.de

Key Words: Anal cancer, metastases, interventional oncology, image-guided intervention, interstitial brachytherapy.
(OS) was reported as 44-78\% (5). Definitive chemoradiation is the standard organ-preserving treatment for localized ASCC (6); after locoregional recurrence, abdominoperineal resection remains the only salvage option. Moreover, about $20 \%$ of patients develop distant metastases after curative treatment (7). After metastatic relapse, the prognosis is poor, with a 5-year survival rate of $18 \%$ and median OS of 8-15 months, reported in small case studies (7-10). Guidelines from the European Society for Medical Oncology (ESMO) state that there is currently no consensus on a standard treatment algorithm considering chemotherapy in advanced or metastatic disease (mASCC); however, in the case of isolated metastatic volume, i.e. oligometastatic disease, surgical resection is a considerable option (5). Yet, in most cases resection is not possible due to the distribution or volume of the lesions, or due to contraindications for surgery or general anesthesia, apart from associated morbidity and mortality. Aside from surgery, a multidisciplinary approach to localized therapy of mASCC might also include imageguided local ablation techniques such as radiofrequency ablation (RFA) or interstitial brachytherapy (IBT). Percutaneous IBT of parenchymal organs is a relatively new technique that is adapted from conventional high-dose-rate brachytherapy (11). In IBT an iridium-192 source is temporarily introduced into metastatic lesions via percutaneously implanted applicators, which are placed under imaging guidance in a minimal invasive intervention, thereby enabling a clearly delineated single-fraction irradiation of the target volume. IBT has already been shown to be an efficient, yet gentle treatment with a minimum of complications in ablation of primary or secondary malignancies at various sites, e.g. colorectal cancer and hepatocellular carcinoma (1214). To our knowledge, no data have been published, so far, evaluating the efficacy of IBT in the treatment of mASCC. In this study, safety and efficacy were retrospectively analyzed in a cohort of patients with unresectable ASCC metastases who underwent image-guided IBT. 
Table I. Characteristics of the patient population and the treated metastases. Prior to interstitial brachytherapy (IBT) all patients received irradiation of the primary tumor; patient 3 refused chemotherapy.

\begin{tabular}{|c|c|c|c|c|c|c|c|c|c|}
\hline Patient & Gender & $\begin{array}{l}\text { Age, } \\
\text { years }\end{array}$ & $\begin{array}{l}\text { Distant } \\
\text { metastasis }\end{array}$ & $\begin{array}{l}\text { Chemotherapy } \\
\text { before IBT }\end{array}$ & $\begin{array}{c}\text { Localization } \\
\text { of target } \\
\text { lesion }\end{array}$ & $\begin{array}{c}\text { Number } \\
\text { of } \\
\text { lesions }\end{array}$ & $\begin{array}{l}\text { Maximum } \\
\text { diameter of } \\
\text { target lesion } \\
(\mathrm{cm})\end{array}$ & $\begin{array}{c}\text { D100 } \\
\text { Administered } \\
(\mathrm{Gy})\end{array}$ & $\begin{array}{l}\text { Local } \\
\text { recurrence } \\
\text { (months } \\
\text { after IBT) }\end{array}$ \\
\hline 1 & $\mathrm{~F}$ & 60 & Synchronous & Cisplatin, 5-FU, mitomycin & Liver, lung & 5 & $0.6-4.0$ & $21.3-32.6$ & - \\
\hline 2 & $\mathrm{~F}$ & 77 & Metachronous & FU, mitomycin & Lymph node & 1 & 1.4 & 21.1 & - \\
\hline 3 & $\mathrm{~F}$ & 46 & Synchronous & - & Liver, lung & 15 & $0.4-2.9$ & $14.7-21.0$ & - \\
\hline 4 & $\mathrm{~F}$ & 51 & Synchronous & Cisplatin, 5-FU, folinic acid & Liver & 6 & $1.0-4.0$ & $14.6-16.2$ & - \\
\hline 5 & M & 66 & Synchronous & Cisplatin, 5-FU & Liver & 1 & 6.2 & 17.1 & - \\
\hline 6 & M & 67 & Metachronous & Cisplatin, 5-FU & Lung & 1 & 2.1 & 24.0 & 7.6 \\
\hline 7 & $\mathrm{~F}$ & 74 & Metachronous & $\begin{array}{c}\text { Cisplatin, 5-FU, } \\
\text { folinic acid, mitomycin }\end{array}$ & Liver & 9 & $0.9-1.7$ & $15.0-17.3$ & - \\
\hline
\end{tabular}

F: Female; 5-FU: 5-fluorouracil; M: male.

\section{Patients and Methods}

Eligibility criteria and patients. Inclusion criteria were: (a) technically unresectable metastases of the anal canal, (b) medical contraindication for resection or severe comorbidities, (c) refusal of surgery, (d) East Coast Oncology Group (ECOG) performance status below 2, (e) appropriate liver parameters (bilirubin $<30 \mu \mathrm{mol} / \mathrm{l}$ ) and sufficient lung capacity (FEV1 >1.5 1) in the case of ablation of hepatic and pulmonary metastases, respectively. No upper limit was placed upon maximum tumor diameter or number of lesions. Contraindications to local ablation were (a) peritoneal carcinomatosis; (b) prognosis limiting, widespread systemic disease; (c) uncorrectable coagulation defects (target values: platelet count $>50,000 / \mathrm{nl}$, international normalized ratio $>1.5$, partial thromboplastin time $<50 \mathrm{~s}$ ); (d) lack of consent. In consideration of these criteria, 7 patients (five female; median age $=66$ years range $=46-77$ years) were included with 38 inoperable metastases. Patient recruitment was blinded and carried out between December 2008 and June 2016. All patients were diagnosed with histologically proven ASCC and displayed tumor progression at the time of referral to our clinic; every case was discussed in an interdisciplinary tumor conference, where the indication for IBT was determined.

Prior to ablation, six patients were treated with concurrent chemoradiation, patient 3 only received radiotherapy of the primary tumor due to refusal of chemotherapy. Patient 6 was treated with abdominoperineal resection after local recurrence. Furthermore, prior to IBT, patient 4 underwent radioembolization of the liver and patient 5 underwent hemihepatectomy (for detailed patient characteristics see Table I). All patients underwent a full evaluation of their clinical status with a physical examination and laboratory assessment. Furthermore, whole-body contrast-enhanced computed tomography (CT) and a gadolinium (Gd)-enhanced magnetic resonance imaging (MRI) (Primovist ${ }^{\circledR}$, Bayer, Pharma, Leverkusen, Germany) was performed to acquire complete staging. All patients undergoing IBT of lung lesions had a clinically fully compensated lung function. Approval of the Ethics Committee for the analysis of the patient data was obtained (EudraCT-No 2011-003220-12).

Interventional technique and irradiation. The applied technique has been described elsewhere in detail $(13,15,16)$. Under guidance of a fluoroscopy-CT (Toshiba, Aquilion, Japan) or real-time MRI using a 1.0-T open MRI scanner (Panorama HFO; Philips Healthcare, Best, the Netherlands) an 18-gauge needle was introduced into the target lesion. A flexible 6-F catheter sheath (Terumo Radifocus ${ }^{\circledR}$ Introducer II, Terumo Europe, Leuven, Belgien) was inserted over a stiff angiography guide wire using Seldinger's technique followed by the placement of a 6-F afterloading catheter (Afterloadingkatheter; Primed ${ }^{\circledR}$ Medizintechnik GmbH, Halberstadt, Germany). The intervention was performed under local anesthesia (lidocaine) and analgo-sedation (midazolam and fentanyl). The number and arrangement of the catheters was determined by the shape, size and location of the target lesion. After catheter positioning, a contrastenhanced CT scan in breath-holding technique or a gadolinium-based MRI scan was obtained to document correct catheter positioning and for irradiation planning. On these images, the target volume was drawn precisely as gross tumor volume (GTV) and clinical target volume (CTV), additionally, organs at risk (OARs; e.g. stomach, duodenum) were marked by the interventional radiologist and the radiooncologist. Dose calculation was performed using the acquired dataset with Oncentra-Masterplan (Oncentra ${ }^{\circledR}$ Brachy treatment planning system; Elekta AB, Stockholm, Sweden). The calculated isodose lines, relative to margins of the CTV, were controlled and adapted slice by slice. All irradiations were administered as singlefraction irradiations using an iridium-192 source with a nominal activity of $10 \mathrm{Ci}$. A reference dose of $20 \mathrm{~Gy}$ was prescribed to our patients, which was defined as the minimum dose enclosing the complete CTV (D100). Higher doses inside the tumor volume were permitted and not limited. Depending on adjacent OARs, dose limitations were taken into account, i.e. gastric or duodenal wall $(<15 \mathrm{~Gy} / \mathrm{ml})$. After irradiation the catheters were removed and the puncture channels were sealed using gelfoam or fibrin tissue glue. Figure 1 illustrates the interventional technique.

Follow-up. After IBT, every 3 months clinical, laboratory and imaging follow-up (contrast-enhanced whole-body CT and GbEOB-DTPA-enhanced MRI of the liver) were performed. Local tumor control (LTC) and progression-free survival (PFS) were assessed by employing RECIST criteria (RECIST version1.1.) (17), OS was calculated from the date of ablation to death. Adverse events were defined according to Common Terminology Criteria for Adverse Events (CTCAE version 4.03) (18). 
Study design and statistical analysis. Primary endpoints were LTC and safety; secondary endpoints were OS and PFS. The results were analyzed in a non-randomized and retrospective approach. LTC, OS and PFS were evaluated employing the Kaplan-Meier method with SPSS (Version 22.0; IBM Corp, Armonk, NY, USA). Safety was evaluated descriptively.

\section{Results}

The median diameter of the target lesions was $1.2 \mathrm{~cm}$ (range=0.4-6.2 cm). Due to size and location of the GTV, 14 liver lesions were treated under MRI guidance (maximum diameter range $=0.4-3.2 \mathrm{~cm}$ ), the remaining 24 lesions were visualized with CT. A total of 28 liver lesions, nine lung metastases and one lymph-node metastasis were treated. All 38 lesions were irradiated in a total of 12 sessions: in three patients, local ablation was completed after one session, three patients underwent two sessions due to progressive disease after 12.8, 2.5 and 2.6 months, respectively. The treatment of patient 3 was split into three sessions due to progression 5.6 months after the first IBT. The median hospital stay was 5 days (range $=3-10$ days); patient 2 stayed 10 days due to evaluation-angiography prior to radioembolization of liver metastases in the same hospital stay. We report four cases of pneumothorax: three required a chest drain (classified as grade 2 adverse event, according to CTCAE 4.03), and one regressed spontaneously. In two patients, we recorded an increased level of systemic inflammation markers (C-reactive protein, and leukocytosis) without fever or additional symptoms; one was treated with i.v. antibiotics (ciproflaxacin and metronidazole) leading to a rapid normalization. Two patients reported unspecific nausea. No severe adverse events (grade 3 or more) were recorded.

The intended minimum tumor dose (D100) was $20 \mathrm{~Gy}$, although the radiotherapy dose had to be lowered in the case of radiation in the vicinity of an OAR and in the case of several liver lesions in order to preserve liver function (at least $33 \%$ of the liver parenchyma should not be irradiated with more than $5 \mathrm{~Gy}$ ) (12). The median administered D100 was 16.2 Gy (range=12.0-32.6 Gy). During the treatment, no adjacent OARs were irradiated in excess of the critical value. The median irradiation time was $30.5 \mathrm{~min}$ (range $=10-40$ min). The median follow-up time was 15.2 months (range=2.5-32.6 months). One patient exhibited local recurrence at the GTV 7.6 months after IBT, resulting in an LTC rate of $97.4 \%$ in the Kaplan-Meier analysis (Figure 2). The recurrent lesion was a lung lesion covered with a minimum tumor dose of $24 \mathrm{~Gy}$ at time of treatment.

PFS ranged from 2.5-32.6 months, with a median of 3.3 months (Figure 3). Patient 5 was excluded from the PFS analysis due to lack of detailed information regarding the time point of disease progression. Within the follow-up period, all patients had systemic progressive disease. In the time between local ablation and systemic progression, four patients received specific tumor therapy, in detail: palliative re-radiation of the recurrent primary tumor, radioembolization of the liver, palliative chemotherapy, and surgical resection plus irradiation of a cerebellar metastasis, respectively. At the date of censoring, one patient of the analyzed population was still alive (patient 1 received treatment in October 2015 and January 2017). The median OS of the remaining patients was 25.2 months (range $=6.5$ 51.0 months) (Figure 4). Survival after recurrence ranged from 3.2 to 32.6 months, with a median of 18.3 months.

\section{Discussion}

Since cancer of the anal canal is a rather rare malignancy with a likelihood of up to $20 \%$ for distant metastases after curative treatment data regarding management of mASCC is scarce. Hence, according to the ESMO guidelines a recommendation cannot be made for a specific palliative chemotherapeutic algorithm in advanced/mASCC. The reported 5-year survival rate remains poor at approximately $18 \%(7,8)$. The existing treatment regimens are extrapolated from those used for SCC of the lung or the cervix and based on case studies or series. Nevertheless, the ESMO guidelines state that fit patients with symptomatic metastatic or recurrent disease not amenable to surgery should be considered for chemotherapy, usually with a combination of cisplatin and 5fluoruracil, which is a well-documented regimen, for instance with a reported median OS of 34.5 months in a case series of 18 patients $(5,19)$. Response is also reported for carboplatin, doxorubicin, taxanes and irinotecan with/without cetuximab or the combinations of these agents but these regimens are less evaluated (20). Furthermore, possible subsequent therapy concerning immune checkpoint inhibition was recently assessed in heavily pretreated patients with metastatic disease or locally advanced recurrent disease: 37 patients were enrolled in a single-arm, phase 2 trial with nivolumab, with a reported median PFS of 4.1 months and a median OS of 11.5 months (21).

In metastatic colorectal cancer, resection of liver metastases has proven to be curative, with 5-year OS rates of $16-74 \%$ (median $=38 \%$ ) (22), although data regarding surgical resection of ASCC metastases are limited. To our knowledge, there is no study evaluating the outcome of an ASCC population after surgery, however, there are two studies investigating the outcome of patients with SCC of any primary site after resection of liver metastases: Omich et al. found a cumulative median OS of 33.3 months and a median PFS of 9.3 months in 28 patients (19 with ASCC) (23); Pawlik et al. reported a cumulative median OS of 22.3 months and a median PFS of 9.8 months (27/52 diagnosed with ASCC) (24). However, in general, surgical resection is applicable to a limited number of cases in metastatic disease, for instance, in metastatic colorectal cancer, curative resection of liver metastases is not 

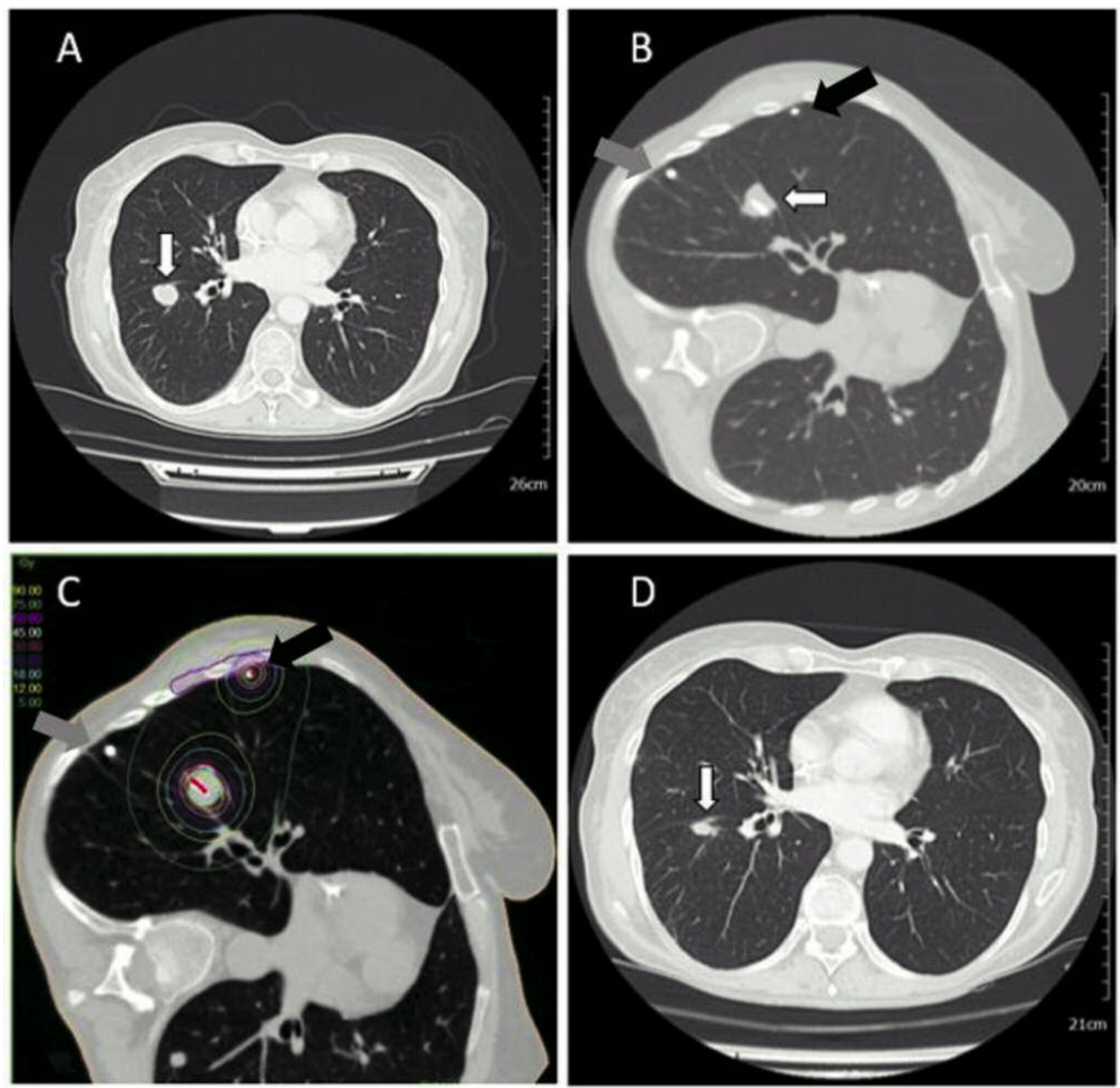

Figure 1. Interventional technique and local tumor control in patient 1 with metastatic anal squamous cell carcinoma (ASCC). A: Pre-interventional contrast-enhanced computed tomographic (CT) slice showing a metastasis of ASCC (white arrow) in the lower lobe of the right lung. The second clinical target volume (CTV) is not depicted in this slice. B: CTV in the lower lobe with one percutaneously implanted brachytherapy catheter (white arrow). A second CTV was located subpleurally in the upper lobe of the right lung (black arrow). C: Planning CT with CTV indicated (red line), catheter (marked in red) and isodose lines for both CTVs in the lower and middle lobe (black arrow). D: Contrast-enhanced CT slice 3 months after interstitial brachytherapy showing partial remission of the treated lesion in the lower lobe (white arrow). The second CTV is not depicted in this slice. Gray arrows: Chest drain.

possible in approximately $80 \%$ of cases (25). Furthermore, liver resection in particular is associated with significant morbidity and mortality, with regard to the extent of resection and the remaining functional liver tissue.
In contrast, image-guided interstitial IBT provides a safe and minimally invasive approach. According to the literature, grade 3-4 adverse events, i.e. bleeding, requiring angiographic embolization, occurs in up to $3 \%(15,26)$. In 


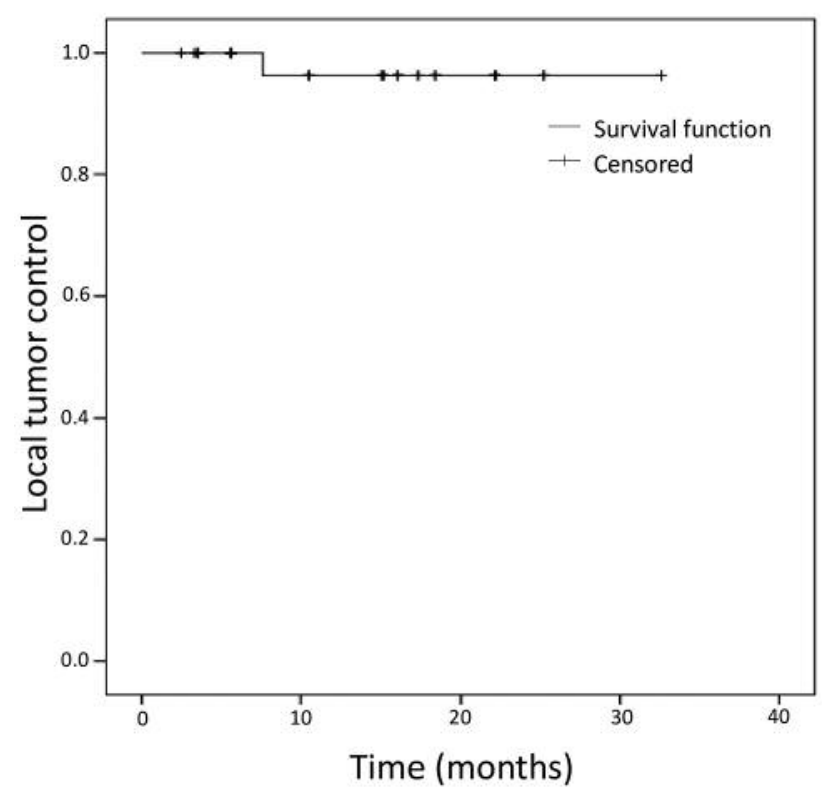

Figure 2. Kaplan-Meier curve for local tumor control after interstitial brachytherapy.

the study herein, we did not report any severe adverse event (grade 3 or more). The median hospital stay was 5 days (range=3-10 days). In general, patients tolerated the treatment well and could have been discharged earlier, but due to the risk of occult bleeding, observation of at least 48 $\mathrm{h}$ after ablation was considered necessary.

IBT has primarily been evaluated in primary and secondary liver malignancies, such as hepatocellular carcinoma and particularly in metastatic colorectal cancer, demonstrating LTC rates of $95 \%$ and $88.3 \%$ after 12 months, respectively. Furthermore, this novel technique has also been shown to provide favorable LTC rates in the ablation of retroperitoneal lesions with LTC rates up to $88 \% 12$ months post IBT (1214). Corresponding with these findings, in the study herein we report an excellent LTC of $97.4 \%$ over a median follow-up of 15.2 months. Referring to the existing literature, numerous studies evaluating the effect and outcome of radiotherapy of the primary tumor are available, however, to our knowledge there are no studies assessing the efficacy of stereotactic body radiation nor of local ablation (i.e. RFA or IBT) in (oligo)metastatic ASCC. However, few published data exist regarding the advantage of an aggressive multidisciplinary treatment (MDT) in an oligometastatic setting: Eng and colleagues evaluated outcomes among 77 patients who received systemic chemotherapy or chemotherapy plus MDT (33 in the MDT group), i.e. surgery (16/33), chemoradiation (14/33) and percutanous RFA (3/33). The MDT group had significantly better median PFS of 16 months and median OS

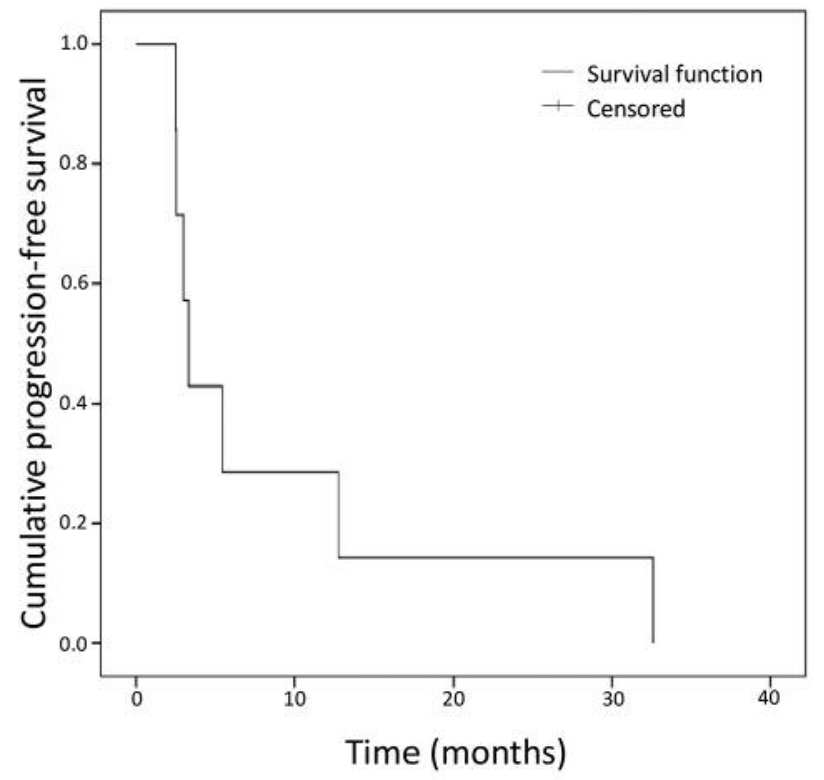

Figure 3. Kaplan-Meier curve for progression-free survival after interstitial brachytherapy.

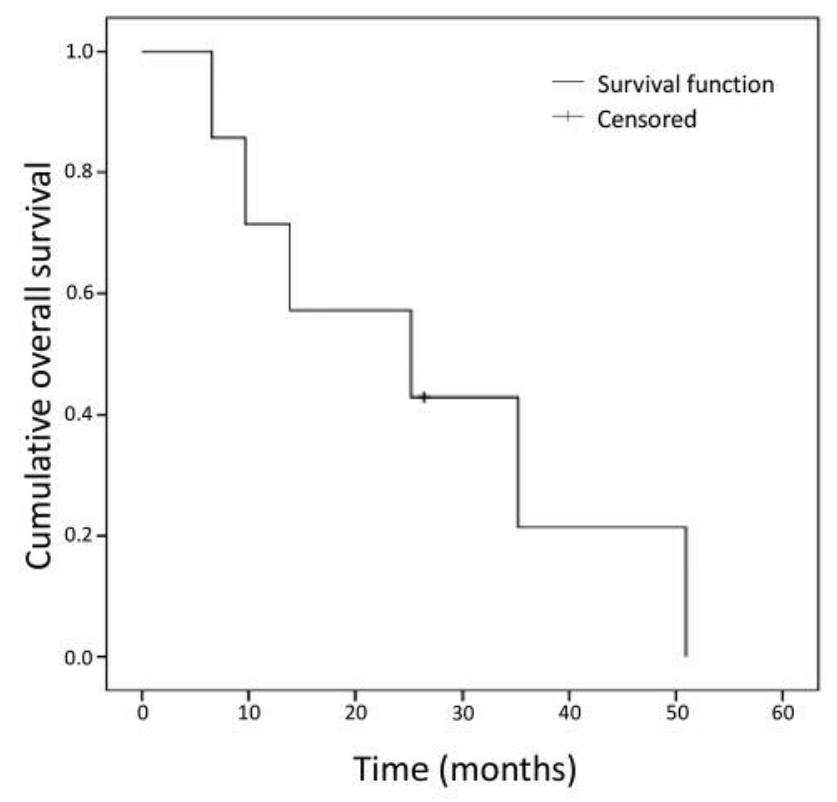

Figure 4. Kaplan-Meier curve for overall survival of six patients treated with interstitial brachytherapy. At the date of censoring, patient 1 was still alive.

of 53 months compared to the median PFS and OS of all patients of 7 and 22 months, respectively (27). All patients were treatment-naive for metastatic disease. Similarly, Evesque et al. split 50 individuals into a chemotherapy group 
and a chemotherapy plus MDT group (30 patients: 13 surgery, 11 radiotherapy, six RFA). Median OS in the MDT group was 22 versus 13 months in the chemotherapy group and median PFS was 10 versus 5 months (28).

In the herein study, we report an inferior median PFS of 3.3 months (range=2.5-32.6 months), possibly based on the fact that we analyzed a small patient population and, additionally, these selected patients were not naïve for metastatic treatment, six out of seven patients showed failure of palliative chemotherapy (one patient refused chemotherapy). We report a median OS of 25.2 months, ranging from 6.5 to 51 months, providing comparable results to the MDT group of Evesque et al. Moreover, we report two long-term survivors: patient 5 with 51 months and patient 7 with 35 months. These findings suggest that highly selected candidates benefit from an aggressive ablative approach even in metastatic disease; furthermore, with knowledge of the survival advantage arising from an assertive MDT approach, IBT provides an additional, well-tolerated and feasible ablative technique in the toolbox against metastatic disease. Furthermore, compared to surgical resection, this method offers advantages in terms of treatment tolerability and accessibility of lesions (in number and location); moreover, compared to RFA as used in the studies mentioned above, IBT is free from technical limitations concerning the potential cooling effect arising from large tumor masses $(>5 \mathrm{~cm})$ or from the vicinity to major vessels close to the GTV resulting in a possible incomplete ablation.

However, limitations of this study are its retrospective nature and the low number of patients; furthermore, the treated patient population comprised of selected patients, heavily pretreated in a metastatic setting with a failure of therapeutic strategy. A prospective trial would be needed to identify appropriate candidates, naïve for metastatic treatment, as well as pretreated, and evaluate the outcome after IBT in a multidisciplinary setting. This could possibly establish IBT in the therapeutic algorithm for mASCC, as has already been implemented in the ESMO guidelines for the management of patients with metastatic colorectal cancer (29). However, given the rarity of ASCC, studies concerning the management of patients in an oligometastatic setting are scarce. Our data demonstrate that IBT can be safely and effectively used in the local control of mASCC.

Moreover, referring to the findings of Eng et al. and Evesque et al., our investigation provides an indication that a more aggressive approach preferably in a multidisciplinary setting might improve the OS of selected patients.

In conclusion, our results confirm that interstitial brachytherapy is a safe and particularly effective therapeutic option in the multidisciplinary management of patients with metastasized squamous cell carcinoma of the anal canal and, moreover, highly selected patients undergoing local treatment might have favorable survival outcomes.

\section{References}

1 Islami F, Ferlay J, Lortet-Tieulent J, Bray F and Jemal A: International trends in anal cancer incidence rates. Int $\mathrm{J}$ Epidemiol 46: 924-938, 2017.

2 de Martel C, Ferlay J, Franceschi S, Vignat J, Bray F, Forman D and Plummer M: Global burden of cancers attributable to infections in 2008: A review and synthetic analysis. Lancet Oncol 13: 607-615, 2012.

3 Martin D, Balermpas P, Winkelmann R, Rodel F, Rodel C and Fokas E: Anal squamous cell carcinoma-State of the art management and future perspectives. Cancer Treat Rev 65: 11$21,2018$.

4 Chaturvedi AK, Madeleine MM, Biggar RJ and Engels EA: Risk of human papillomavirus-associated cancers among persons with AIDS. J Natl Cancer Inst 101: 1120-1130, 2009.

5 Glynne-Jones R and Nilsson PJ, Aschele C, Goh V, Peiffert D, Cervantes A and Arnold D: Anal cancer: ESMO-ESSOESTRO clinical practice guidelines for diagnosis, treatment and follow-up.

6 Bartelink H, Roelofsen F, Eschwege F, Rougier P, Bosset JF, Gonzalez DG, Peiffert D, van Glabbeke $M$ and Pierart $M$ : Concomitant radiotherapy and chemotherapy is superior to radiotherapy alone in the treatment of locally advanced anal cancer: Results of a phase III randomized trial of the European Organization for Research and Treatment of Cancer Radiotherapy and Gastrointestinal Cooperative Groups. J Clin Oncol 15: 2040-2049, 1997.

7 Eng C: Anal cancer: current and future methodology. Cancer Invest 24: 535-544, 2006.

8 Johnson LG, Madeleine MM, Newcomer LM, Schwartz SM and Daling JR: Anal cancer incidence and survival: The Surveillance, Epidemiology, and End Results experience, 1973-2000. Cancer 101: 281-288, 2004

9 Abbas A, Nehme E and Fakih M: Single-agent paclitaxel in advanced anal cancer after failure of cisplatin and 5-fluorouracil chemotherapy. Anticancer Res 31: 4637-4640, 2011.

10 Jhawer M, Mani S, Lefkopoulou M, Hahn RG, Harris J, Catalano PJ and Haller D: Phase II study of mitomycin-C, adriamycin, cisplatin (MAP) and bIeomycin-CCNU in patients with advanced cancer of the anal canal: An Eastern Cooperative Oncology Group study E7282. Invest New Drugs 24: 447-454, 2006.

11 Kotsuma T, Yamazaki H, Masui K, Yoshida KEN, Shimizutani K, Akiyama H, Murakami S, Isohashi F, Yoshioka Y, Ogawa K and Tanaka E: Brachytherapy for buccal cancer: from conventional low dose rate (LDR) or mold technique to high dose rate interstitial brachytherapy (HDR-ISBT). Anticancer Res 37: 6887-6892, 2017.

12 Ricke J, Wust P, Stohlmann A, Beck A, Cho CH, Pech M, Wieners G, Spors B, Werk M, Rosner C, Hanninen EL and Felix $\mathrm{R}$ : CT-guided interstitial brachytherapy of liver malignancies alone or in combination with thermal ablation: Phase I-II results of a novel technique. Int J Radiat Oncol Biol Phys 58: 14961505, 2004.

13 Collettini F, Lutter A, Schnapauff D, Hildebrandt B, Puhl G, Denecke T, Wust P and Gebauer B: Unresectable colorectal liver metastases: Percutaneous ablation using CT-guided highdose-rate brachytherapy (CT-HDBRT). Rofo 186: 606-612, 2014. 
14 Mohnike K, Wieners G, Schwartz F, Seidensticker M, Pech M, Ruehl R, Wust P, Lopez-Hanninen E and Gademann G, Peters $\mathrm{N}$, Berg T, Malfertheiner P and Ricke J: Computed tomographyguided high-dose-rate brachytherapy in hepatocellular carcinoma: Safety, efficacy, and effect on survival. Int J Radiat Oncol Biol Phys 78: 172-179, 2010.

15 Bretschneider T, Ricke J, Gebauer B and Streitparth F: Imageguided high-dose-rate brachytherapy of malignancies in various inner organs-technique, indications, and perspectives. J Contemp Brachytherapy 8: 251-261, 2016.

16 Ricke J and Wust P: Computed tomography-guided brachytherapy for liver cancer. Semin Radiat Oncol 21: 287-293, 2011.

17 Eisenhauer EA, Therasse P, Bogaerts J, Schwartz LH, Sargent D, Ford R, Dancey J, Arbuck S, Gwyther S, Mooney M, Rubinstein L, Shankar L, Dodd L, Kaplan R, Lacombe D and Verweij J: New Response Evaluation Criteria In Solid Tumours: Revised RECIST guideline (version 1.1). Eur J Cancer 45: 228 247, 2009.

18 National Cancer Institute: Common Terminology Criteria for Adverse Events (CTCAE) v4.03, 2010. Available from: https://evs.nci.nih.gov/ftp1/CTCAE/CTCAE_4.03/CTCAE_4.03_2 010-06-14_QuickReference_5x7.pdf (last accessed 26 July, 2018).

19 Faivre C, Rougier P, Ducreux M, Mitry E, Lusinchi A, Lasser P, Elias D and Eschwege F: 5-Fluorouracil and cisplatinum combination chemotherapy for metastatic squamous-cell anal cancer. Bull Cancer 86: 861-865, 1999.

20 Hainsworth JD, Burris Hr, Meluch A, Baker M, Morrissey L and Greco F: Paclitaxel, carboplatin, and long-term continuous infusion of 5-fluorouracil in the treatment of advanced squamous and other selected carcinomas: Results of a Phase II trial. Cancer 92: 642-649, 2001.

21 Morris VK, Salem ME, Nimeiri H, Iqbal S, Singh P, Ciombor K, Polite B, Deming D, Chan E, Wade JL, Xiao L, Bekaii-Saab T, Vence L, Blando J, Mahvash A, Foo WC, Ohaji C, Pasia M, Bland G, Ohinata A, Rogers J, Mehdizadeh A, Banks K, Lanman R, Wolff RA, Streicher H, Allison J, Sharma P and Eng C: Nivolumab for previously treated unresectable metastatic anal cancer (NCI9673): A multicentre, single-arm, phase 2 study. The Lancet Oncology 18: 446-453, 2017.

22 Kanas GP, Taylor A, Primrose JN, Langeberg WJ, Kelsh MA, Mowat FS, Alexander DD, Choti MA and Poston G: Survival after liver resection in metastatic colorectal cancer: Review and metaanalysis of prognostic factors. Clin Epidemiol 4: 283-301, 2012.

23 Omichi K, Mizuno T, Okuno M, Tzeng CD, Conrad C, Chun YS, Aloia TA and Vauthey JN: Long term outcome after resection of liver metastases from squamous cell carcinoma. Eur J Surg Oncol 43: 2129-2134, 2017.
24 Pawlik TM, Gleisner AL, Bauer TW, Adams RB, Reddy SK, Clary BM, Martin RC, Scoggins CR, Tanabe KK, Michaelson JS, Kooby DA, Staley CA, Schulick RD, Vauthey J-N, Abdalla EK, Curley SA, Choti MA and Elias D: Liver-directed surgery for metastatic squamous cell carcinoma to the liver: Results of a multi-center analysis. Ann Surg Oncol 14: 2807-2816, 2007.

25 Garden OJ, Rees M, Poston GJ, Mirza D, Saunders M, Ledermann J, Primrose JN and Parks RW: Guidelines for resection of colorectal cancer liver metastases. Gut 55: iii1-iii8, 2006.

26 Mohnike K, Neumann K, Hass P, Seidensticker M, Seidensticker R, Pech M, Klose S, Streitparth T, Garlipp B, Benckert C, Wendler JJ, Liehr UB, Schostak M, Goppner D, Gademann G and Ricke J: Radioablation of adrenal gland malignomas with interstitial high-dose-rate brachytherapy: Efficacy and outcome. Strahlenther Onkol 193: 612-619, 2017.

27 Eng C, Chang GJ, Nancy You Y, Das P, Rodriguez-Bigas M, Xing Y, Vauthey J-N, Rogers JE, Ohinata A, Pathak P, Sethi S, Phillips JK, Crane $\mathrm{CH}$ and Wolff RA: The role of systemic chemotherapy and multidisciplinary management in improving the overall survival of patients with metastatic squamous cell carcinoma of the anal canal. Oncotarget 5: 11133-11142, 2014.

28 Evesque L, Benezery K, Follana P, Tuan Falk A, Doyen J, Reure J, Cavaglione $G$ and François E: Multimodal therapy of squamous cell carcinoma of the anus with distant metastasis: A singleinstitution experience. Dis Colon Rectum 60: 785-791, 2017.

29 Van Cutsem E, Cervantes A, Adam R, Sobrero A, Van Krieken JH, Aderka D, Aranda Aguilar E, Bardelli A, Benson A, Bodoky G, Ciardiello F, D'Hoore A, Diaz-Rubio E, Douillard JY, Ducreux M, Falcone A, Grothey A, Gruenberger T, Haustermans K, Heinemann V, Hoff P, Köhne CH, Labianca R, Laurent-Puig P, Ma B, Maughan T, Muro K, Normanno N, Österlund P, Oyen WJG, Papamichael D, Pentheroudakis G, Pfeiffer P, Price TJ, Punt C, Ricke J, Roth A, Salazar R, Scheithauer W, Schmoll HJ, Tabernero J, Taïeb J, Tejpar S, Wasan H, Yoshino T, Zaanan A and Arnold D: ESMO consensus guidelines for the management of patients with metastatic colorectal cancer. Ann Oncol 27: 1386-1422, 2016.
Received July 12, 2018

Revised July 28, 2018

Accepted August 6, 2018 